\title{
12. Project findings: an agenda for action
}

\section{A. J. Brown and Chris Wheeler}

\section{A new picture of whistleblowing}

In this book, new research has revealed that far from being rare, whistleblowing is a relatively common and routine activity in a majority of public sector agencies. Part 1 of the book showed that in the four jurisdictions studied, on a conservative estimate, 12 per cent of employee survey respondents had acted as public interest whistleblowers in their organisation over two years. Even if often problematic, whistleblowing is a natural feature of public sector life.

The research also showed that, contrary to the bleak picture of whistleblowing as a crisis in which every whistleblower is destined to suffer for their experience, a majority of officials who reported public interest concerns - on average, at least 70 per cent - regarded management and colleagues as having treated them either the same or well as a result. There remains another side to both these stories. In some agencies and circumstances, the incidence and seriousness of reprisals are very much greater than this average and, even when direct reprisals are not involved, whistleblowing often involves stresses, tensions and problems for individuals and organisations alike. At least as many public officials who observe wrongdoing also continue to choose not to report, citing lack of confidence in the management response and in management support.

Nevertheless, the research shows that it is far from inevitable that whistleblowers need suffer for their experience or that, when employees make disclosures, nothing will be done. The organisational and social importance of whistleblowing is well recognised in many public agencies. This new picture of whistleblowing provides public sector managers with good reason to invest in strategies for encouraging staff to blow the whistle on perceived wrongdoing within their organisation, in ways that will enable them to be better managed and will help lead to more positive outcomes.

Part 2 of the book has shown the need for this greater institutional investment. In the jurisdictions studied, major challenges remain to be overcome before it can be said that all that can reasonably be done, is being done to manage whistleblowing productively. Many public agencies have actively grappled with the issue of how to encourage staff to disclose perceived wrongdoing and even the difficult issue of how to protect staff from reprisals should they do so. There remain, however, substantial differences in outcomes depending on the circumstances in which wrongdoing is seen and whistleblowing occurs. Some 
organisations are encouraging and managing whistleblowing more successfully than others. Agencies that make more credible efforts are achieving more positive results and are therefore showing the way for the development of best practice; but their relative success confirms that many more systems are patchy and are missing out on achieving more positive outcomes.

This chapter draws together the major lessons of the research, for what can and should be done to improve current approaches to whistleblowing in the Australian public sector-within individual agencies and at a whole-of-government level in the jurisdictions studied. As outlined in Chapter 1 , these conclusions are drawn from the research to date as a whole-including the results of the empirical surveys conducted across the participating agencies, assessment of the comprehensiveness of agency procedures, comparative analysis of the different legislative regimes in place and the researchers' assessments of the relationships between these different elements of governments' overall responses to whistleblowing. While there are variations between jurisdictions and agencies in the extent of some challenges, there are also major challenges that exist right across the board. This chapter focuses on action to address these major challenges.

The first part of the chapter summarises some main lessons and challenges from the research to date, for those ultimately responsible for the management of whistleblowing. These include case-handlers and other managers responsible for the internal integrity systems of agencies, chief executives and senior management and governments as a whole. The discussion highlights the importance of the internal processes by which agencies respond to and encourage whistleblowing and the important role of individuals within these processes. It also highlights the evidence that many agencies are currently making insufficient institutional efforts to actively address the management of whistleblowing, even when subject to statutory requirements.

The second part of the chapter draws on these lessons to state 10 key findings from the research, identifying priority areas for action. In summary, the research shows a particular need for:

1. more comprehensive agency systems for recording and tracking employee reports of wrongdoing

2. agency procedures for assessing and monitoring the risk of reprisals or other conflict for those who report

3. clearer and better advice for employees on the range of avenues available for reporting wrongdoing

4. basic training for public sector managers in how to recognise and respond to possible public interest disclosures

5. a program of training for internal investigators in basic techniques, with special attention given to issues of internal witness management 
6. adoption and expansion of structured support programs for employees who report wrongdoing

7. improved mechanisms for monitoring the welfare of employees who report wrongdoing, from the point of first report

8. more detailed and flexible agency procedures for the investigation and remediation of reprisals and breaches of duty of care

9. a dedicated oversight agency or unit for the coordination of responses to employee-reported wrongdoing

10. legislative action to provide more effective organisational systems and realistic compensation mechanisms and to recognise public whistleblowing.

More detailed recommendations regarding current and prospective best practice in agencies are the subject of a further, second report from this project. The final part of this chapter briefly outlines some of this continuing analysis, along with areas for future research.

\section{Lessons and challenges}

The purpose of recognising and facilitating public interest whistleblowing - and the research in this book - is to help create environments in which individual public officials are willing and able to speak up when concerned about possible wrongdoing. Fortunately, the new evidence from earlier chapters confirms that in the Australian public sector today, it is often possible for public officials to blow the whistle, have their concerns acted on and not suffer reprisals. In many organisations, speaking up about serious concerns is accepted as a natural part, if not duty, of the life of a public servant. The research also shows that when officials are able to report wrongdoing internally with confidence that action will be taken, the outcomes are often positive. Many of the data confirm that when an official's concern is to stop or prevent wrongdoing, the fastest and safest way to achieve this, in the bulk of instances, is by speaking up and reporting through official channels.

At the same time, the research has confirmed that reporting wrongdoing is rarely an easy experience. In any situation, it is inherently difficult for employees to draw attention to suspected wrongdoing or organisational failures without the risk of personal or organisational conflict. The challenge for many, if not most, employees who report their concerns lies in the management of these risks. Employees who assess the risks accurately, have good coping skills and good personal support networks are those best placed to manage the process to a reasonable conclusion and to exit their role as a whistleblower having served the public interest and survived. Employees who are less good at anticipating and managing conflict, or who exacerbate it, are inevitably at higher risk of negative outcomes, even if their primary concerns are correct. These outcomes 
can reverberate not only for the individual, but for colleagues, managers and the entire workplace.

In every jurisdiction studied, employees are entitled by law to rely on the support and protection of the management of their agency if or when they report concerns about wrongdoing through appropriate channels. The crucial questions become, how safe is it currently for employees to rely on that support and protection and what can be done to increase the extent to which the trust of employees and the wider public are justified in respect of institutional responses? The research holds several key lessons for integrity managers, chief executives, senior management and governments as a whole.

\section{Case-handlers and integrity managers}

The most important overall lesson for those responsible for integrity matters within agencies is the crucial importance of their own role. Chapter 4 showed in detail that the majority of public employees who reported wrongdoing did so internally - in the first instance and even if they went on to make a subsequent disclosure. Only a small minority of public employees are prepared to make disclosures outside their organisation, and then principally only after first having made one or more internal disclosures. These results indicate that the first, internal responses to public interest disclosures are the most crucial and could be the only opportunities for concerns about wrongdoing to be brought to light at a point when the problems remain manageable. In this context, the research results translate into six key lessons for those with responsibility for the internal integrity systems of agencies.

\section{Quality internal investigations are crucial}

First, the quality, conduct and outcomes of internal assessments and investigations are vital factors on which rest many of the results of any whistleblowing process. As demonstrated by Chapters 5 and 6 , the professionalism of an agency's systems for assessing and investigating possible wrongdoing will determine not only whether the primary issues are identified and problems rectified; they will bear directly on whistleblowers' experiences of reporting, their level of stress, the risk that they will suffer reprisals or become engaged in organisational conflict and on the messages that pass to other employees about whether the organisation is a safe environment in which to speak up.

While following through on internal investigation outcomes is the responsibility of management, those responsible for investigations typically have the best and often the only opportunity to help the agency resolve difficult issues without them becoming unnecessarily damaging to individuals and the organisation. The data in Chapters 4-6 show that once the whistle is blown, the investigation outcome becomes crucial to many employees' chances of survival and is perceived 
by them as such. Especially until other support strategies for whistleblowers are strengthened, in what can become an unexpectedly stressful process for many individuals, the investigation is often all that whistleblowers have on which to pin their hopes. At the same time, if doubts arise about what action is being taken, or if initial investigations do not deal with all the key issues, the potential for disputation, delay, internal organisational conflict and further investigations increases. Apart from the quality of the primary outcome, those assessing disclosures and undertaking and overseeing internal investigations have special responsibility for:

- ensuring that whistleblowers' expectations of and understandings about internal processes are as realistic as possible

- regularly communicating with whistleblowers as to what action is being taken in relation to their disclosure

- regularly meeting or communicating with whistleblowers to identify continuing issues or issues that have arisen since an original disclosure, so that these can be appropriately addressed or answered.

\section{Recognise the gatekeeper roles of managers}

The second challenge for integrity managers is recognising the full extent to which first and second-level line managers currently act as the gatekeepers for receipt of the bulk of possible public interest disclosures. Previously, and in legislation in some jurisdictions, it has often been assumed that managers simply manage and if an official needs to make a disclosure, they will use separate internal processes to do so - such as an internal hotline or by reporting to an auditor or internal investigation staff. The reality is different. The bulk of disclosures first come to the knowledge of direct supervisors or, if they are not trusted by employees, another higher or similar manager. Integrity managers need to frankly assess and frankly advise senior management as to how well line managers are equipped in their agencies to handle this role.

Integrity managers also need to recognise the dual roles that line managers play in such circumstances, as described in Chapters 6, 7 and 9. Direct supervisors could be the best people to provide support and protection to a whistleblower - or they could be the greatest source of any risk of conflict and reprisals. It can no longer be assumed that the role of integrity-related staff will not cut across the traditional responsibilities of line managers for issues raised by or with their staff, because it is now clear that line managers are handling a much more important and sensitive range of internal integrity matters than might have been previously realised. 


\section{Stronger alternative reporting avenues}

A further particular lesson arising from the large proportion of disclosures received by supervisors is the need for integrity managers to revisit their strategies for educating employees about the different avenues available for reporting. In line with the findings below, this may require some reconception of the roles of integrity practitioners within the organisation and particularly their visibility and accessibility. The research strongly suggests that employees will most often make disclosures to people they already know. Unless integrity-related staff are widely known and perceived as trustworthy and approachable in an organisation, attempts to encourage disclosures to be made directly to points other than the normal management chain-where this is desirable - could have limited effect. For some agencies, however, making integrity staff more visible (for example, through training and internal outreach) is not a priority strategy.

\section{Recognise and develop whistleblower support roles}

It is now clearer than before that integrity practitioners play different roles in the welfare of employees who report. When agencies have dedicated support programs, with staff other than investigators and line managers tasked with helping oversee the welfare of whistleblowers, this is an emerging new specialist role in its own right. As discussed below, however, as a challenge for senior management, such programs are currently relatively few and far between, and organisationally weak. The research in Chapters 5, 8 and 9 also confirms that investigators should not be relied on to provide internal witness support, for the simple fact that their investigation role often directly conflicts with the role of a trusted source of personal guidance and support. This reinforces the need for agencies to invest in more organised, alternative support strategies.

In the absence of these stronger programs, internal integrity staff members currently continue to play vital support roles, in conjunction with their traditional core business (investigation, risk assessment, standard setting, complaint handling, workplace education). Chapter 9 shows that these support roles do not rate as strongly as might have been expected. At present, however, whistleblowers are also most likely to survive largely on their own personal resources and with the support of personal and professional networks (including friends, family, colleagues and unions). Only in a minority of cases is there evidence that an 'anti-dobber' mentality in workplaces results in withdrawal of this crucial collegiate support. Survival is often largely thanks to the support of line managers, where this is possible. Chapter 9 showed that when the support of line managers is not likely, not possible or not forthcoming, or is withdrawn, internal integrity staff again become the first port of call in terms of institutional support. This situation needs to be addressed. 


\section{Develop investigators' roles in reprisal risk assessment}

The fifth lesson is that, while integrity staff with investigation roles should not be relied on for support, integrity managers can develop clearer strategies for the roles that investigators can play, consistent with their core business, in helping ensure the welfare of whistleblowers. One crucial role, at the outset of cases, lies in the field of the assessment of reprisal risk. Another associated role lies in the provision of 'pre-emptive' investigation of the whistleblower's work environment in order to put support staff and management in a better position to establish — should issues arise later — whether reprisals or mismanagement of a whistleblower have occurred. Chapter 6 sets out a comprehensive new picture of the risk factors associated with whistleblowing cases in which mistreatment is later alleged. Chapters 5, 6 and 9 demonstrate the difficulties that agencies have in resolving whether mistreatment has occurred. In the last part of this chapter, Findings 2, 7 and 8 point to some key actions to enable internal integrity staff to play more structured and strategic roles in the prevention and resolution of adverse outcomes.

\section{Work with integrity agencies}

The final lesson is that internal integrity systems cannot be expected to resolve all issues satisfactorily, all of the time, without external help. Many whistleblowing cases can be resolved internally, to the satisfaction of all concerned, with the public interest served. By their nature, however, there will always be whistleblowing cases in which internal integrity systems cannot resolve conflicts between individual employees and the organisation as a whole, either because the internal investigation outcome is not favourable to the whistleblower or because it has not been possible to satisfactorily manage the welfare of the whistleblower. Agencies do sometimes get it wrong and public employees might even go on to blow the whistle publicly, and be justified in doing so - an issue for legislative recognition, as discussed in Chapter 11.

In between internal and public whistleblowing, however, lie the crucial roles that external integrity agencies can play in better assisting agencies to manage more cases to positive conclusions and to deal more expeditiously with those cases that should not or cannot be resolved internally. Without abrogating their own responsibility for these cases, integrity managers need to look to a new partnership with external agencies in the management of whistleblowing and help identify those roles that they think external integrity agencies can usefully play, as well as the resources and skills needed to enable them to do so. Similarly, external integrity agencies need to help build this partnership and be ready and able to assist in ways that have not previously been possible. The need for legislative and institutional reform in support of this new partnership is discussed further below. 


\section{Chief executives and senior management}

\section{Whistleblowing is a positive resource for management}

The same research provides eight major lessons for the senior management of the agencies studied. A first important lesson is that whistleblowing is, for the most part, a positive force for the good management of public sector organisations. Whistleblowing is valuable. Even if employee disclosures often involve other personal and workplace issues, the information they hold has been proven to be vital in the detection and remediation of wrongdoing, ranging from the minor to the most serious cases. In Chapter 2, the surveys of the case study agencies' own managers and case-handlers confirm that in their assessment, the information provided by whistleblowers is generally significant and valuable and represents the single most important source of information for the purposes of uncovering wrongdoing. As shown in Chapters 2 and 5, a large proportion of whistleblower reports are substantiated and lead to necessary management action - a larger proportion than is often the case in respect of allegations or complaints from all sources.

Whistleblowing therefore has proven organisational value. The likelihood is also increased that, when it is not heeded, or it is mismanaged, the same accurate information will eventually surface among external integrity agencies or the wider public. It is in the interests of chief executives to shift from seeing whistleblowing and whistleblowers as a problem-should they hold that view - to instead invest in systems to enable employees to report perceived wrongdoing more easily, and earlier. This includes more integrated systems for recognising the different public and private interest elements that are frequently caught up in disclosures, for the purposes of ensuring that these are all professionally dealt with, as reflected in Finding 1.

\section{All staff members are, and should be, potential whistleblowers}

It is often easy for senior managers to assume that there are particular personal characteristics that drive particular employees to blow the whistle. Anecdotally, it is also common for chief executives and senior managers to assume that most whistleblowers are difficult and disgruntled individuals predisposed to conflict, who represent more of a hindrance than a help to the smooth functioning of a busy agency. Any such view is, however, likely to be biased by the fact that it is cases like this that are the most likely to become intractable problems and therefore come to senior management attention - whether because of the nature of the individuals or the case or because it has already been mismanaged. Statistically, a far higher number of whistleblowing cases involve internal disclosures that, even when made for mixed motives or associated with a history of conflict, are successfully investigated and resolved, often to the benefit of the agency. Because of this simple fact, especially in large agencies, senior 
managers are less likely to ever be troubled by the details of this larger number of cases, or ever know the identity of the whistleblowers involved.

On a more general scale, the evidence that personal characteristics can predict whistleblowing - for example, that whistleblowers are slightly more likely to be female and to have spent longer time in their organisations - pales against the evidence that, depending on the issue and context, almost any employee can eventually be driven to blow the whistle on perceived wrongdoing. As demonstrated in Chapter 3, employees who report are difficult to distinguish from those who do not, on basic measures such as job satisfaction and organisational citizenship. Indeed, there is good reason to surmise that most conventional employees do not rush to blow the whistle, but rather persist for some time in workplaces in which they perceive there to be problems. What is most clear, from Chapter 3, is that staff will typically blow the whistle when matters become sufficiently serious and if they believe their disclosure will make a difference or serve some good purpose. The responsibility of agencies is to ensure that the value of disclosures is realised in a way that further inspires the trust of others.

\section{Equipping managers to be reliable gatekeepers}

While these basic results provide good reason for senior managers to take the management of whistleblowing more seriously, a challenge arises from the evidence of where and how the bulk of employees are currently first disclosing their concerns. The fact that the bulk of whistleblowing currently occurs within agencies, rather than to outside agencies or the public, places a heavy responsibility on agencies to manage reporting well. This responsibility is increased by the fact that within agencies, the bulk of reporting takes place directly to supervisors and other line managers, rather than other points in the organisation. The extent of the reporting that first occurs this way means every manager must be equipped to recognise and deal appropriately with a wide range of disclosures, many of which trigger particular statutory obligations as well as responsibilities of the agency as an employer. These results reinforce the need for more comprehensive systems of recording and tracking the handling of alleged wrongdoing cases. As will be discussed, the same results confirm that junior managers are often not the ideal people to first receive disclosures or to be the only ones to receive them - increasing the need for review and education about the different available reporting avenues for staff, as discussed in Finding 3.

To the extent that first and second-level managers also often are appropriate first recipients, and are likely to retain that role, the research also identifies that most managers are not familiar with their obligations and perceive themselves to be in need of greater training. In addition to the broad evidence in Chapter 7, Chapter 10 showed the problem to be sometimes acute. In some agencies, the 
confidence of managers in the quality of internal whistleblowing procedures was high, when the agency really had no such procedures at all. Meeting the need for basic managerial training is the challenge reflected in Finding 4.

\section{Whistleblowers continue to be treated unjustly}

A fourth challenge lies in the fact that, while a majority of whistleblowers indicate that they are treated well or the same in their organisations, on average, a sizeable minority do continue to suffer. Moreover, the data in Chapter 5 showed that in some agencies, the proportion of public interest whistleblowers who reported mistreatment ranged towards 50 per cent. The risk factors for reported mistreatment, described in Chapter 6 , show that the cases with better outcomes tend to be simpler, easier and lower level in terms of the number and seniority of the people involved. In more complex cases, many agencies continue to struggle to prevent damaging conflicts from arising or to control the risk of real reprisals being taken against reporters. This active mistreatment comes on top of some of the often natural, unavoidable negative impacts of reporting processes, such as increased stress.

The need for more comprehensive management and reporting systems (above) as well as more active support strategies (below) is reinforced by the fact that it is not colleagues or co-workers who represent the most important sources of perceived mistreatment. Contrary to many impressions and the design of much whistleblowing legislation, the major sources of perceived mistreatment are managers. This is especially the case in circumstances in which managers are themselves implicated in or compromised by the alleged wrongdoing, but it also reflects the failure of managers to provide support and guidance to employees, to control the risks of reprisals being taken by others or to recognise when problems affecting an employee's work performance or workplace relationships are related to the difficult experience of having reported wrongdoing. These data confirm the complex dual role of line managers as potentially the most important source of support for employees who report, but alternatively also the people most likely to 'shoot the messenger' or leave a whistleblower exposed to preventable and controllable conflicts, as a means of trying to end a troublesome incident or exit a troublesome process.

\section{Management responses are crucial to ensuring reporting}

The fact that managers appear to represent the major source of the problems experienced by whistleblowers is not something that senior management can afford to ignore. Chapter 3 demonstrated two overwhelming reasons why many staff currently did not report wrongdoing: because they assessed that nothing would be done or because they believed they would be exposed to, and not protected by management from, reprisals. As shown in Chapter 2, an average of 29 per cent of public employees who observed very or extremely serious 
wrongdoing neither reported it nor took any action, even when no-one else had reported it. This 'inaction rate' rises to more than 60 per cent in some agencies. Chief executives can ill afford to preside over organisations in which confidence in the management response to reporting is low. Poor or negligent treatment of whistleblowers has direct impacts on whether other members of staff are prepared to report or take other action in response to perceived wrongdoing. It therefore impacts on the ability of management to ensure that wrongdoing is identified and addressed early, rather than being allowed to fester or emerge first in the public domain.

Clearly, a positive reporting climate cannot be fostered in organisations in which managers' own mistreatment or mishandling of whistleblowers goes unaddressed. While the dual roles of line managers as both custodians of and threats to the welfare of whistleblowers raise complex problems, managerial reprisals and mishandling of reporting processes have too many far-reaching implications to be simply written off as inevitable and unavoidable problems. Chief executives and senior managers face legal responsibilities, as employers, for the welfare of staff members who fulfil their duty to report. They can be held responsible for allowing a workplace environment to develop in which more junior managers fail to properly manage reprisal risks, let alone feel they can undertake direct reprisals. An agency's public reputation, including its reputation as a preferred employer, can suffer severely if it becomes known as one that fails to provide systems and procedures that deliver organisational justice.

\section{Current whistleblowing procedures are weak, especially on issues of support}

The sixth challenge for senior managers lies in the fact that, objectively assessed, the typical quality of agency procedures and systems for the management of whistleblowing is not strong. Despite statutory requirements in many cases, some agencies continue to have, in effect, no specific systems or procedures for encouraging and managing whistleblowing. While some agencies do have more comprehensive procedures, it is not a large number. In most cases, such procedures are not comprehensive and they are particularly weak on mechanisms for supporting and protecting those employees who report. Chapter 10 assessed only five of 175 agencies nationally as having developed reasonably strong procedures for the management of whistleblowing, measured against the current Australian Standard.

At present, whistleblowers who survived the experience were most likely to have done so thanks to their own personal skills and support networks, the fact that their disclosure was able to be substantiated and because they happened by chance to have a manager who was willing and able to support them. The formal management systems of the majority of organisations currently do little to ensure or increase the likelihood of such outcomes. As a default, senior 
managers instead tend to extend support only in those cases that appear to involve the 'perfect' whistleblower-but these are not the cases in which intervention is most likely to be needed. The data suggest that, logically, institutional investment is most needed in those cases with the highest risk of conflict, which are likely to be the more 'murky' and complex cases.

This project's second report will deal further with new, best-practice models for effective internal witness management systems. However as reflected in Finding 6,. As reflected in Finding 6, it is already clear that the bulk of agencies, in most jurisdictions, need to give active and urgent consideration to strategies for providing whistleblower support. In particular, agencies need to develop programs, commensurate with their own size and needs, for ensuring that support strategies are directed and, where necessary, directly delivered, by people with an institutional role that conflicts as little as possible with the challenges often implicit in providing that support. As seen above, an employee's line managers can be crucial sources of support - but this cannot be relied on and in some situations the reverse will be true. Similarly, internal investigation and other integrity staff can be crucial, but their role can also involve direct conflicts. In most cases, and all higher-risk ones, chief executives must ensure that someone with institutional independence from both the whistleblower's chain of command and the investigation response is tasked to monitor and direct the provision of support.

\section{Support programs must be properly resourced}

The research has also shown that for whistleblower support programs to be effective, they must be more than a token. Such programs must be given resources and organisational status commensurate with the level of need in individual agencies, given their size and likely desirable incidence of reporting. They also need to be embedded in management systems that ensure the support program can be triggered early in all the most needy cases. The evidence shows, in Chapter 9, that so far, even in large agencies, such programs are functioning at a fraction of the scale at which they need to operate to make a real difference. Only perhaps 1.3 per cent of all likely public interest whistleblowers are currently appearing on the 'radar' of active support programs, even in the project's case study agencies - or about 6.5 per cent of all public interest whistleblowers who reported being mistreated. Findings 1 and 6 summarise the actions needed to address these issues.

\section{Management support must be active}

As also shown in Chapter 9, and underscored by Chapter 6, management strategies for actively protecting whistleblowers are in need of development. The research has generally confirmed that agencies have the option of three broad responses when employees report wrongdoing: trusting in the 
confidentiality of the matter, to prevent anyone from knowing the whistle has been blown; doing nothing and hoping that problems do not arise or will dissipate naturally; and intervening actively in the workplace to ensure that relevant employees know that an employee has management's support. Currently, agencies rely heavily on the first response, even though confidentiality is likely to work only as medium to long-term protection in a limited number of cases. If agencies wish to address the problem of staff confidence in the likely or known response of management to reporting, and really protect those who report, procedures and systems must be in place to support active intervention when needed. Such strategies also require strong commitment from the leaders of any organisation, to the highest level.

\section{Leadership}

Finally, the research confirms that the tone of an organisation's responses to issues of integrity and wrongdoing is set from the top. As shown throughout the book, and particularly in Chapters 2, 5 and 10, the extensive differences in performance and outcome between agencies are not easily explained by jurisdictional or legislative differences nor by the differing nature of the core business of agencies. Instead, the differences point to the individualised nature of agency responses to the challenges of whistleblowing. In some cases, chief executives and their management teams are overseeing systems that, even if capable of improvement, are delivering good outcomes. In many more agencies, the management team has either given low priority to the issue or is struggling to find a workable formula.

The importance of management leadership carries through into the question of how, even if whistleblower support is extended, its effectiveness is ultimately to be judged. The evidence in Chapters 5, 6 and 9 suggests that in most agencies, most managers know that more can be done to positively manage whistleblowing cases and that, when poor outcomes occur, this is because not enough has been done to prevent reprisals and other adverse consequences. The confidence of employees that senior management will support staff who fulfil their responsibility to report depends less on what management says than on what it does in response to notable cases - including cases that could have been better managed. Having better equipped all managers to discharge the agency's duty of care to its employees in such circumstances, chief executives must be seen to ensure that justice is done and to admit responsibility when, for whatever reason, agencies fail to meet the necessary high standards. 


\section{Lessons for government}

\section{Whole-of-government responsibility}

The research holds four major lessons for Australian governments. First, it is clearly in the interests of governments at all levels to get the management of public interest disclosures right. History shows that when disclosures are not properly dealt with and whistleblowers are not treated appropriately, this can have a detrimental, long-term impact, not only on individuals and individual agencies, but on the reputation of the government of the day and on levels of trust in government as a whole.

Until now, governments have attempted to address the management of public interest disclosures largely through important but symbolic statements of policy through legislation, with individual public sector agencies left to implement the detail, largely unassisted and often unsupervised. Until now, there has also been a relative dearth of information regarding even the simple extent of whistleblowing, let alone how it might be better managed. With that gap now smaller, it is important for governments to adjust-or, in the case of the Commonwealth Government, to introduce - their legislative framework to work in practical ways to achieve the desired outcomes.

\section{Lifting the standard of agency systems and procedures}

Second, as part of this reform process, it is clear that governments have a responsibility to ensure that their agencies bring their approaches to whistleblowing up to a more comprehensive and consistent standard. There is some way to go before this occurs. The broad policy setting of requiring individual agencies to shoulder the primary burden of managing employee disclosures productively, as public employers, has been shown by the research to be valid. The similarity of overall outcomes between jurisdictions, notwithstanding very different legislative settings, contrasts sharply with the great diversity of outcomes obtained by agencies within all the jurisdictions studied. This confirms that it is at the agency level that the major decisions matter - and at which most attention needs to be directed.

Nevertheless, it is clear that there is a long way to go before a majority of individual public sector agencies are maximising their chances of gaining improved outcomes for themselves and their staff. While the research indicates that current whistleblowing legislation has positive effects in building the expectations of public employees that they can safely report, this promise is not necessarily being effectively met by agencies. Governments must now shoulder their responsibility for ensuring that agencies are equipped, empowered and required to do so. 
The primary actions needed to do so are laid out in Chapter 11 and summarised by Findings 9 and 10 below. They include the need to extend new resources to integrity agencies to let them undertake the vital coordination and oversight roles on which effective implementation partly depends.

\section{Legislating from first principles}

Governments need to particularly recognise that effective whole-of-government frameworks for the management of public interest whistleblowing cannot realistically operate at their current level of abstraction. They need to be underpinned by clearer first principles and more detailed operational arrangements. These include clearer standards and processes by which the whistleblowing procedures of agencies can be developed, implemented and judged. The fact that a large proportion of public interest whistleblowing is probably going unreported and therefore effectively unmanaged under present laws is just the first sign of the need for a more comprehensive approach. The second major sign is the evidence, discussed earlier, of the even smaller proportion of public interest whistleblowers coming into contact with the types of internal witness support strategies contemplated by most legislation.

While the next steps in a second generation of legislative frameworks include more detailed operational and oversight frameworks for agencies, there are also important issues of principle involved in effective legislative reform. Perhaps in order to avoid an anticipated flood of disclosures, most Australian public interest disclosure legislation has been relatively complicated, technical and restrictive in its application. As argued in Chapter 11, the consequence has been laws that are difficult to administer - when in fact they should err on the side of catching more, rather than less, public officials within their ambit if they are to support public employees and agencies taking an 'if in doubt, report' approach. Addressing these issues, in the face of misplaced concerns that a less technical approach might somehow encourage more whistleblowing than currently occurs, requires political will and clarity of legislative purpose.

\section{Effective legislative support for basic outcomes}

Finally, legislative reform needs to reapproach, from first principles, two of the major objectives of whistleblowing legislation that have never been properly delivered, despite up to 15 years' experience in some jurisdictions. Most Australians would be relatively astounded to know that despite the evidence of the importance of whistleblowing, and the knowledge that whistleblowers have suffered, no public official is believed to have yet been able to secure formal compensation for damage to their career under whistleblower protection legislation. Similarly, most Australians would find it nonsensical that no whistleblower protection law extends adequately to the regulation of public whistleblowing, even though this is the most obvious and legally risky example 
of the phenomenon. As outlined in Chapter 11, and in the findings below, government action to reform existing whistleblowing regimes is unlikely to be judged to be credible by the broader public, whose interests are intended to be protected by such disclosures, unless such basic issues are meaningfully addressed.

\section{Key findings: an agenda for action}

What are the areas in which action is most clearly needed and in which it can most clearly lead to better outcomes? The research to date has found 10 key areas warranting particular attention and action. The first eight of these findings specify areas in which action can be taken on an agency and a whole-of-government basis, while, as outlined above, the final two findings involve legislative change and whole-of-government action.

\section{More comprehensive agency systems for recording and tracking employee reports of wrongdoing}

Most agencies currently lack sufficiently comprehensive systems for recording and tracking employee reports of wrongdoing. Some agencies still have no such systems. As shown by Chapters 2, 8, 9, 10 and 11, these systems are a basic prerequisite for effective monitoring of how many public interest disclosures are being made, what investigation or other action is being taken and how those involved in the disclosures are being managed, at an agency and a whole-of-government level.

Even more importantly, such systems are basic to enabling the senior management of agencies to know what disclosures are being received at junior and middle-management levels - which is where the bulk of disclosures are currently received (Chapter 4) and where the key risks of mismanagement, mistreatment or reprisal currently arise (Chapters 5 and 6). For all these reasons, integrated systems need to be put in place that:

- allow senior management to track reports and report-related issues wherever they are being dealt with throughout the organisation, including informally by lower-level managers

- record and track wrongdoing reports in a coordinated way, together with other forms of complaints, grievances and conflicts

- record and track all reports that could possibly be classified as public interest disclosures (PIDs) under legislation, not just reports that staff have requested be treated as PIDs or that evolve into more serious cases

- require all reports to be assessed at the outset for the level of reprisal risk or other conflict associated with the making of the report, classified according to risk, and routinely monitored for any change in risk level (see also Finding 2). 


\section{Agency procedures for assessing and monitoring the risk of reprisals (or other conflict) for those who report}

The research found that a majority of agencies had no systematic methods in place for ensuring that when employees reported wrong doing, assessments were made as to what if any risks of reprisal or mistreatment surrounded that report (Chapters 6, 9 and 10). Such procedures are basic prerequisites for the effective management of disclosures if agencies are to anticipate and minimise problems rather than trying to deal with them only in an ex post facto fashion. Without the information afforded by early assessment of risk, agencies also leave themselves unable to properly defend themselves against later allegations of having mismanaged employees who make disclosures.

While further recommendations about effective risk-assessment procedures are also the subject of the project's second report, it is clear that standard procedures for risk assessment should:

- be triggered by all initial reports, rather than only in response to employee requests or after problems arise (see also Finding 1)

- be simple and flexible, so as to be efficiently administered by all first and second-level managers, with more detailed assessment requirements triggered only on an as-needs basis

- take a broad view of possible sources of problems (that is, identify and assess indirect sources of conflict or difficulties as well as direct reprisal risks)

- involve the employee(s) making the disclosure (that is, reflect and address their self-assessment of risk as well as objective assessment)

- include a third party, trusted by the employee(s) making the disclosure, who will be involved in helping them manage their own responses to risks

- ensure that the risk assessment is recorded

- ensure that the risk assessment is updated as necessary

- trigger meaningful support arrangements, protection measures or other management action.

\section{Clearer and better advice for employees on the range of avenues available for reporting wrongdoing}

Agencies need to actively review their strategies for informing staff about the range of reporting avenues that are open to them and which avenues might be most appropriate in different circumstances. Chapter 4 showed that the bulk of disclosures were made directly to supervisors or managers in the normal management chain, rather than to internal specialist areas, hotlines or integrity agencies. While reporting to supervisors and line managers is not to be discouraged, the research demonstrates the importance of the initial responses made to disclosures - in terms of investigation action and control of reprisals or 
other conflicts - and therefore who it is who first receives a disclosure (Chapters 5, 6, 8 and 9).

Employees who are considering reporting need to know it is also possible - and could be preferable - to not make their disclosure directly to a supervisor or line manager and that they may also make their disclosure directly and confidentially to other points in the organisation or to an external integrity agency (and, if so, which points and which agency). While further recommendations about reporting paths and workplace education are also the subject of the project's second report, the precise arrangements and strategies needed are likely to be specific to individual agencies. The research indicates that agencies need to do more to ensure that, in as many cases as possible, employees direct their concerns about wrongdoing to the most appropriate place, in the first instance.

\section{Basic training for public sector managers in how to recognise and respond to possible public interest disclosures}

Chapters 7 and 8 demonstrated that most managers in the agencies studied did not have a practical understanding of their responsibilities under public interest disclosure legislation and considered themselves in need of more training about their obligations and how to fulfil them. With first and second-level managers currently receiving the bulk of wrongdoing reports (Chapter 4), this lack of understanding can do much to explain why more reports are not being accurately identified as possible public interest disclosures (Chapters 2 and 11), why major reprisal risks are not being identified and addressed (Chapter 6) and why available support mechanisms are not being triggered in more cases (Chapter 9).

These results make it clear that agencies should not be giving supervisory responsibilities to first and second-level managers without first providing basic training to managers about how to recognise and respond to employees' concerns regarding wrongdoing in the organisation. The basic training should be:

- simple

- comprehensive (that is, including the different ways to respond to a range of information or allegations about wrongdoing, not simply the technical requirements of public interest disclosure legislation)

- geared towards an 'if in doubt, report' approach to employee concerns, by ensuring that managers trigger the agency's procedures in respect of all possible public interest disclosures, not simply those that they consider especially serious or doubt their own ability to handle. 


\section{A program of training for internal investigators in basic techniques, with special attention to issues of internal witness management}

Chapter 8 identified the need for a higher level of available expertise and consistency of approach and performance in the way in which agencies investigated employee reports of wrongdoing. There is a clear need for agencies to ensure that they have available to them staff with sufficient training in all relevant types of investigation, including 'evidence-based' investigations (for example, those that could result in disciplinary or criminal action) and 'outcome-focused' investigations (for example, investigations into administrative action or inaction, failures to follow procedures or inadequate procedures and policies). Chapters 5, 6 and 9 also showed that while internal investigators should not carry responsibility for supporting and protecting agency whistleblowers, they played vital roles in the process that required a higher level of training.

Only limited professional training is currently available in Australia that meets all these needs and is suitable for the bulk of agencies. The need to develop new training is also taken up below in relation to Finding 9. As part of the process of developing the appropriate training approaches, agencies need to:

- evaluate existing performance and conduct more comprehensive assessments of their training needs in these areas

- maximise those training opportunities currently available in the tertiary and commercial sectors

- where resources permit (that is, in larger agencies), dedicate new resources to the development of agency-specific training

- when using external investigation resources, such as consultants, take responsibility for ensuring they have the necessary expertise

- work more closely with external integrity agencies to ensure they are using appropriately trained investigators, including consultants, and ensure the development of new training packages to help meet their needs.

\section{Adoption and expansion of structured support programs for employees who report wrongdoing}

As discussed earlier, Chapters 9 and 10 showed that only a limited number of agencies had active programs for supporting and protecting employees who reported wrongdoing. Only about half of all agencies surveyed had procedures for supporting employees in these circumstances, with many of these only informal procedures, and only 11 per cent of all agencies had a formalised program for the provision of internal witness support.

Further, even when programs are more formal, agency systems are not ensuring these are accessed by a large proportion of those employees who could benefit from support. In the agencies and the period studied, perhaps only 1.3 per cent 
of all public interest whistleblowers - or 6.5 per cent of those who reported mistreatment - received the benefit of such a program.

The description of current and prospective best practice in internal witness management programs is the subject of the project's second report. The existing identified elements of an internal witness management system, developed in collaboration with the project's case study agencies, are set out in Appendix 3. The precise requirements will vary greatly between different agencies. It is, however, already clear that most agencies do not have any such program at all, often notwithstanding statutory requirements, and that even when agencies do have formalised programs, these need to be extended. In particular, there is a widespread need for agencies to put in place official support strategies that:

- are accessible to all employees who might potentially need them, triggered proactively rather than only reactively (see also Finding 1)

- are based on an active risk-assessment and management approach (see also Finding 2)

- recognise and maximise the role of informal networks as well as formal supervision and professional services in the provision of support (Chapter 6)

- are resourced to deal with the likely real need within the agency and not just selected cases (as suggested by Chapters 2, 5 and 6)

- provide formal recognition to employees who report, as appropriate in individual cases, as well as evaluation of their treatment and follow-up monitoring of their welfare.

\section{Improved mechanisms for monitoring the welfare of employees who report wrongdoing, from the point of first report}

Chapters 5, 6 and 9 demonstrated the need for more effective strategies for responding to alleged and suspected reprisals or other mistreatment of internal witnesses. The research indicates that the most common sources of perceived mistreatment are management-related and involve workplace-based harassment and negative personnel action against whistleblowers taken either directly or indirectly as a result of the whistleblowing incident. Chapters 2 and 5, however, also confirm that public interest whistleblowing frequently arises in conjunction with other conflicts; and Chapter 9 confirms that even when it is clear that adverse actions have been taken, agencies often have difficulty separating justified management actions from those that represent an unjust or inappropriate reprisal against a whistleblower.

These results indicate a need in most agencies for a procedure that allows independent verification of the organisational position (for example, work performance) of employees who report wrongdoing, as close as possible to the 
exact point at which they first report it. It is clear that part of the difficulty in establishing whether the treatment of a whistleblower is or is not justified lies in evidentiary difficulties as to whether particular problems associated with an employee's relationships with colleagues or supervisors began before, simultaneously with or subsequent to a disclosure issue arising.

While the nature of a best-practice procedure will be further explored in the second report, elements of such a procedure include:

- clear documentation as to when and how concerns about wrongdoing were first aired

- collection by the relevant investigator of the evidence existing at the time of the report regarding the reporter's work performance and workplace relationships, undertaken with the knowledge and participation of the reporter

- when the fact of a report is still confidential, alternative strategies such as a general audit of the work histories of all employees in the relevant section to establish the relative position of the employee, in parallel with the primary investigation.

This procedure is above and beyond procedures for the investigation of real allegations regarding reprisals or failures in duty of care, discussed below-because the above actions would be taken as a matter of routine, as a proactive measure to help resolve later issues in case they arise and as a preventive measure against unjustified actions being taken.

\section{More detailed and flexible agency procedures for the investigation and remediation of reprisals and breaches of duty of care}

As discussed in Chapters 8, 9 and 10, a majority of agencies have no specific procedures for the investigation and remediation of alleged or suspected reprisals against whistleblowers. In these circumstances, the default procedure is to investigate such an allegation as if it were the same as any other allegation of wrongdoing, notwithstanding its much greater complexity. Further, as shown in Chapter 11, in most jurisdictions, a reprisal is a criminal offence, requiring proof beyond reasonable doubt that an identifiable individual has taken detrimental action, not otherwise justified, and taken it in response to the act of whistleblowing. As a consequence, unless someone is first found criminally liable, it becomes difficult for agencies to establish that an employee has suffered unjustly in less direct ways - let alone admit any vicarious liability for the actions or inactions of individual managers, and take steps to remediate the injustice.

Resolving the inconsistencies caused by the conjunction of criminal and civil remedies for detrimental action is partly an issue for law reform, as discussed in Chapter 11. These results, however, also show the need for most agencies to: 
- develop specific procedures for dealing with alleged reprisals, where they do not already exist

- frame their procedures more broadly than simply the identification of specific acts of reprisal for which individuals might be held culpable (in a criminal or disciplinary sense), and also recognise more generalised causes and sources of detrimental impacts for which the agency should take responsibility (including impacts that were reasonably foreseeable by individuals but not prevented - that is, negligent; and impacts that were preventable in hindsight, if the agency had had better procedures or had been exercising a higher standard of care).

\section{A dedicated oversight agency or unit for the coordination of responses to employee-reported wrongdoing}

As discussed in Chapter 11, there is a clear need for legislative reform to task an appropriate agency or unit in each jurisdiction with the role of coordinating and overseeing the responses of agencies to public interest whistleblowing. Given the extent of the challenges confirmed by the research, and the state of systems and procedures in most agencies, a more coordinated approach is required, capable of delivering greater consistency and quality in agency-level responses and allowing earlier intervention in investigations or specific problems of internal witness management where needed.

As outlined in Chapter 11, the responsibilities of the oversight agency should include:

- being notified by agencies of all possible public interest disclosures and recording those disclosures and how they were dealt with and resolved

- having the option to decide, on being notified of a disclosure, to provide advice or direction to an agency on how the disclosure should be handled, to manage the investigation of the disclosure by the agency or to take over the investigation of the disclosure

- providing advice or direction to agencies on the steps that should be taken to protect people who have made disclosures or to provide remedial action for a person who has suffered detriment as a result of making a disclosure

- promoting the objectives of the legislation, within government and publicly, and conducting training (see Findings 4 and 5) and public education

- publishing model procedures for the administration of the legislation, with which agencies' internal procedures must be consistent

- conducting a public review of the operation of the legislation at least once every five years.

Given that these resource-intensive responsibilities involve reviewing, assessing and assisting with individual cases, the most appropriate existing agencies to undertake this oversight role would be ones with experience and roles in 
investigations and case-handling, rather than agencies whose roles primarily involve policy and broad standard setting.

Care needs to be taken to ensure that, if an oversight body is created, agencies are still encouraged to manage disclosures at the local level. The research consistently points to the need for a new, coordinated partnership between line managers, agencies' central units and senior management and external integrity agencies. Any oversight agency also needs to be properly resourced and skilled to play the necessary guidance and support roles in relation to primary investigations, reprisal investigations and the handling of complex issues of employee welfare and whistleblower management.

\section{Legislative action to provide more effective organisational systems and realistic compensation mechanisms and to recognise public whistleblowing}

Chapter 11 sets out the key principles for the design of best-practice public interest disclosure legislation resulting from the research. The effective management of public interest whistleblowing in all jurisdictions now hinges, at least in part, on the quality of the legislative approach. In particular, as discussed in the previous chapter, there is need for legislative reform to:

- implement more effective operational systems for the management of whistleblowing - including a more comprehensive 'if in doubt, report' approach to the management of disclosures; minimum standards for internal disclosure procedures in agencies (to be further informed by the second report); and a new framework for coordination and oversight

- address the current lack of practical remedies for public officials whose lives and careers suffer for having made a public interest disclosure

- better protection for public officials who justifiably go public with their concerns.

\section{Future research}

As already noted, the second report from this project will supplement the above findings with a more detailed guide to current and prospective best practice for the management of whistleblowing at an organisational level. This research focuses on the 15 case study agencies and includes further comparative analysis of the quantitative data relating to those agencies, interviews with individual whistleblowers, case-handlers and managers, review of written procedures and operational systems and workshops with agency representatives.

From the studies undertaken so far, six priority areas for future research can also be identified: 
- longitudinal research on how agencies are handling whistleblowing matters, including reporting, inaction and mistreatment rates, in order to measure whether legislative and procedural reforms are having an effect

- longer-term tracking of the life and career outcomes of a wide cross-section of public interest whistleblowers, recognising that participants in the present studies were restricted to those who had reported wrongdoing within the previous two years

- further research into options for practical internal witness support and management intervention as an alternative or adjunct to strategies based primarily on confidentiality

- closer study of the handling of reprisal allegations in whistleblowing cases, to identify with even greater precision why such cases are so complex, and how and by whom they can be best handled and resolved

- closer study of the forms of compensation available to employees who suffer adverse outcomes from reporting, including informal compensation and the positive action taken by agencies to extend justice, and how these efforts might be more effectively supported by the broader legal and management frameworks surrounding workplace relations in the public sector

- more detailed analysis of the training needs of agencies.

While the conclusions reached in this chapter show that institutional responses to whistleblowing have a long way to go, this new picture of public sector whistleblowing shows it will be worth the effort to travel the necessary distance. These data show that, in a field of policy and public management that previously looked wholly bleak, many more of these complex conflicts are being, and can be, resolved in a positive manner. By managing whistleblowing better, outcomes can be found that are just to individuals, serve the long-term interests of organisations and better discharge our institutions' wider obligations to transparency and public integrity. 